\title{
Orchestrators of Innovation-Driven Regional Development: Experiences from the INNOFOKUS Project and Change2020 Programme
} Mervi Rajahonka, Toni Pienonen, Riikka Kuusisto, and Jari Handelberg

\author{
"Be the change that you wish to see in the world." \\ Mahatma Gandhi (1869-1948) \\ Leader of the Indian independence movement
}

\begin{abstract}
The article takes a practical view of regional innovation ecosystems and presents ways to advance more efficient uses of public funding instruments by regional developers. Documenting the views of Finnish regional developers into two workbooks and a toolbox, the results of the INNOFOKUS project and its Change2020 development programme identified that promoting a high-impact project culture and smart specialization in Finland requires a continuous learning and participation process. Key individuals who can make this happen are innovation orchestrators who facilitate activities and compose the big picture. This article aims to bring forth an overview of the building blocks of an enriching and energizing environment and high-impact projects, and it presents an overview of how to enable the work of innovation orchestrators, who play a critical role in facilitating innovation ecosystems.
\end{abstract}

\section{Introduction}

The dawn of the 2014-2020 programme period of the European Union (EU) coincides with the financial crisis facing the European economy. Funding instruments are expected to generate more results with less money. The EU has introduced "smart specialization" strategy for research and innovation (also referred as RIS3) as a new innovation policy concept designed to promote the efficient and effective use of public investment in research. Its goal is to boost regional innovation in order to achieve economic growth and prosperity, by enabling regions to focus on their strengths. In its emphasis and design, the new smart specialization agenda differs from previous regional innovation policies in the respect that universities have a potentially fundamental role to play in its delivery (Kempton et al., 2014). In Finland, European project funding is one of the most important regional development tools for the higher education institutions and their networks, but the new conditions require a new mindset to answer questions such as: What makes a good public development project? and How can higher education institutions contrib- ute more to society with projects? At the same time, the Finnish regions are at different stages in adopting smart specialization - some are pioneering it with participatory processes while laggards are either treating the subject of smart specialization as business as usual or are confused by uncertain expectations.

The INNOFOKUS project and its Change2020 programme developed tools for learning-driven regional development to tackle these questions. Throughout the year 2014, the programme studied these topics and organized several opportunities to clarify these issues. Following dozens of participatory workshops and bench-learning events for hundreds of participants, the project summarized the results under two perspectives that this article attempts to outline: i) a thematic perspective, consisting of the toolbox - 10 elements or themes for enriching and energizing the project environment, and ii) a project perspective, including a model for high-impact projects.

The article is organized as follows. After this introduction, we present a short review of the literature on in- 


\title{
Orchestrators of Innovation-Driven Regional Development
}

\author{
Mervi Rajahonka, Toni Pienonen, Riikka Kuusisto, and Jari Handelberg
}

novation-driven regional development. After that, we discuss the methodology and data. Next, we elaborate the findings of the INNOFOKUS project, first from thematic perspective of ensuring an enriching project environment and then from the perspective of high-impact projects, including the role of orchestrators. Finally, we conclude by discussing the findings and key implications of the project.

\section{Literature Review on Innovation-Driven Regional Development}

Kolehmainen and colleagues (2015) state that innovation is currently central to most EU economic and regional development funding programmes, and that the EU-led smart specialization agenda is a good example of that trend. Furthermore, they claim that knowledgebased and innovation-driven regional development calls for certain kinds of actors, activities, and collaborative practices, and therefore the concepts of "triple helix" and "quadruple helix" are relevant. The concept of triple helix was introduced by Etzkowitz and Leydesdorff (1995) around the idea that universities and business and public sector organizations nurture innovation and economic prosperity of the region together. The concept of quadruple helix adds one more actor group to the triple helix, namely the wider community: people. These concepts are kin to the "system of innovation" approach, which was introduced by Lundvall in 1985. According to innovation system theory, innovation and technology development result from complex relationships among actors in the system, which includes enterprises, universities, and research institutes. Freeman (1988) introduced the expression "national innovation system", and the concept was later applied to regions with the expression "regional innovation system".

In the innovation management literature, the term "innovation orchestration" has been used to describe the activities of a hub firm in developing, managing, and coordinating an inter-firm innovation network (Ritala et al., 2009). Launonen (2015) describes the orchestration of innovation networks as "a process of creating conditions and support infrastructure whereby innovation can emerge and be sustained." Klerkx and Aarts (2013) claim that the innovation literature seems to neglect the difficulties, paradoxes, and dilemmas in innovation network orchestration, as well as the notion that multi-organizational innovation networks can become politicized negotiation arenas. Operating in innovation networks is thus not easy: several challenges and paradoxes exist, balancing between new and existing rela- tionships, openness and closure, and informal and formal relationships, as well as finding correct ways of interacting. Kolehmainen and colleagues (2015) point out that, because each actor of the collaboration network has its own vision concerning its own future and the future of the whole region, it is important to have joint processes for forming shared visions concerning the region. This in turn requires actors - organizations or individuals - who are capable of visioning between visions (Kolehmainen et al., 2015; Sotarauta et al., 2007).

In this process of shaping joint and shared visions, regional leadership is needed, calling for enthusiasm and the ability to motivate and energize different actors. However, different people or actor groups may be in charge of the process at different stages of the development process. There is a need for people that have a connecting role in local and regional networks, acting as brokers in interweaving the networks and explaining objectives for different stakeholders (Kolehmainen et al., 2015). Launonen (2015) depicts orchestrators as requiring interpersonal, facilitation, and design skills. They have to master balancing and negotiation. In terms of network stability, orchestrators must be able to influence, vision, motivate, as well as to solve problems and manage change. Klerkx and Aarts (2013) complement this view, describing that the work of "innovation champions" should be to orchestrate and operate on different levels within networks and innovation communities. They state that the key tasks of innovation network orchestration are vision articulation, matchmaking, and process management. In their conclusion Klerkx and Aarts state that different orchestration roles are ever changing in the innovation networks and communities, emerging over time via informal and formal interaction.

The Japanese approach brings up yet another perspective on orchestration: the concepts of "Ba" and the "SECI" cycle (i.e., socialization, externalization, combination, and internalization), as described by Nonaka and Konno (1998). These concepts help to summarize what type of practical steps need to be taken to facilitate the generation of new knowledge and learning. According to Nonaka and Konno, Ba is a shared physical or virtual space that serves as a foundation for knowledge creation. It is a serendipitous environment where the participants feel safe to share and contribute. There are different types of $\mathrm{Ba}$, each related to a different phase of the SECI process that demonstrates how new knowledge is created by a cycle of interaction, experi- 


\title{
Orchestrators of Innovation-Driven Regional Development
}

\author{
Mervi Rajahonka, Toni Pienonen, Riikka Kuusisto, and Jari Handelberg
}

mentation, and interaction between people (Konno, 2015; Nonaka \& Konno, 1998). Also, Kolehmainen and colleagues (2015) argue that there is a need for regional forums and arenas in which shared visions can be discussed and shaped among different quadruple helix actor groups. Moreover they claim that formal written contracts with common goals are also needed.

\section{Methodology}

The INNOFOKUS project was implemented between 2012 and 2015. It was funded by the European Social Fund and the Finnish Ministry of Education and Culture, and it was managed by the Aalto University School of Business Small Business Center. The Change2020 development programme was a part of the operations carried out by the INNOFOKUS project. The predecessor of the INNOFOKUS project had been the Orchestration-Inno project, which had developed innovative project activities and project skills at the project-operator level. During the Orchestration-Inno project and its training and networking activities, the messages from the project-operations level had highlighted the need to develop the approaches used by the project organization towards more innovative and networked models. Also, the Finnish Ministry of Education and Culture had implemented a study that revealed that the project organizations have a lot of room for improvement, for example, with respect to the quality of project activities and related support services. Therefore, in the INNOFOKUS project and its Change2020 programme, the key target group were $R \& D$ organizations, especially higher-education institutions. The objective was to develop better cooperation models for organizations for regional development as well as tools and operations models for project organizations to pursue learning-driven regional development. Throughout the year 2014, the programme studied these topics and organized several opportunities for different stakeholders involved with regional development, R\&D, and innovation practices to clarify these issues. The project and the programme worked as a platform for co-creation and bench-learning for the participants, as well the project group.

This article documents the project process and empirical data, first from participatory bench-learning events, and second, from semi-structured interviews. The Orchestration-Inno project acted as a case-owner during the 2011 Aalto Camp for Societal Innovation (ACSI) for a challenge named "ESF [European Social Fund] Actors
Creating New Collaboration \& Networking Models to Increase the Impact of Societal Innovations" (tinyurl.com/nv62hj7). The ACSI is an action-learning camp addressing societal concerns in a new and effective manner: it initiates a continuing process empowering people and organizations to think and act, creating shared understanding of how opportunities for societal innovation emerge, and how to use them constructively in business and research. At the same time, participants apply innovation skills to address challenging real-life issues. The prototype co-created as an outcome of the Orchestration-Inno project's challenge at the ACSI 2011 was further developed and realized during the INNOFOKUS project as a tool called "Toolbox - 10 Themes for Creating More Innovative Projects and Working environments".

Before Change2020 started during the years 2012 and 2013 , the INNOFOKUS project arranged or participated in more than ten events in which the themes of the project were discussed with small and large audiences. During 2014, the Change2020 programme arranged four two-day workshops and five shorter events. Through the Change2020 programme, every participating organization brought together a development team and determined their own development process, linked to the themes of the INNOFOKUS project. In the workshops, these development processes were elaborated inside the teams and together with other organizations' teams in bench-learning sessions. Professional facilitators were used in the workshops. Additionally, 13 people were interviewed during October and November 2014. The interviews lasted between 40 to 100 minutes, and in them, new innovative models for high-impact projects were discussed, along with the Toolbox themes. The interviewees were from seven different organizations: two from funding organizations, four from universities, and seven from universities of applied sciences. All the discussions in the events, as well as the interviews, were recorded and detailed notes were drawn up for the purpose of analysis. Based on the material, two practical workbooks (Pienonen \& Markkanen, 2014a, b) and a toolbox were compiled for the project organizations to use in their regional development work. This article is compiled based on the material and all the learnings the INNOFOKUS project group has gained during the project. Table 1 gives an overview of the empirical material used in the process and for this article. In the next three sections, we discuss the findings and conclusions of the INNOFOKUS project and the Change 2020 programme. 


\title{
Orchestrators of Innovation-Driven Regional Development
}

\author{
Mervi Rajahonka, Toni Pienonen, Riikka Kuusisto, and Jari Handelberg
}

Table 1. Empirical material used in this article

\begin{tabular}{|c|c|c|}
\hline Data Source & Purpose & Outcome \\
\hline ACSI 2011 & $\begin{array}{l}\text { European Social Fund actors creating } \\
\text { new collaboration and networking } \\
\text { models to increase the impact of } \\
\text { societal innovations }\end{array}$ & $\begin{array}{l}\text { A prototype consisting of Toolbox themes } \\
\text { for enriching and energizing the project } \\
\text { working environment }\end{array}$ \\
\hline $\begin{array}{l}\text { INNOFOKUS Change } 2020 \text { programme: } \\
\text { Four workshops and five other } \\
\text { co-working events }\end{array}$ & $\begin{array}{l}\text { To facilitate bench-learning between } \\
\text { regional groups working for smart } \\
\text { specialization strategies (e.g., regional } \\
\text { developers, education actors) } \\
\text { - To develop tools for regional groups } \\
\text { to use in their regional development } \\
\text { activities and for developing the RIS3 } \\
\text { strategies into practice }\end{array}$ & Two workbooks and the Toolbox \\
\hline Interviews (13) & $\begin{array}{l}\text { To discuss the toolbox themes and } \\
\text { new innovative project models for } \\
\text { regional development }\end{array}$ & $\begin{array}{l}\text { Two workbooks and a further developed } \\
\text { and tested Toolbox }\end{array}$ \\
\hline
\end{tabular}

\section{Thematic Perspective: The 10 Toolbox Themes}

The ten Toolbox themes listed below were developed by an international multidisciplinary team of experts participating in a co-creative process during an earlier Orchestration-Inno project at ACSI 2011:

1. Creating Great Beginnings (always remember facilitation)

2. Creating Art of Projects (how to break the prison of traditional project management thinking)

3. Building to Last and Expand (thinking beyond the project lifecycle)

4. Creating Networks for Talent Hunting (recognizing individual competences, appreciating and making connections, knowing people, and creating or identifying a network of connectors or mediators)

5. Investing in Networking (face-to-face networks and virtual forums)

6. Co-Creative Collaborative Thinking (game spirit as part of co-creative work; benefits, interests, continuous communication)

7. Promoting Informal Ways of Working (collaboration and co-creation; energizing working environments)
8. Promoting Transparency (sharing information openly, tolerating the feeling of incompleteness and risk taking during the transitory phases of development processes, and minimizing rigid planning based on end results)

9. Identifying Enablers (seeing problems as challenges and looking for the enablers instead of barriers; where to find inspiration; how to open a closed mind)

\section{Being Visual (learning to visualize)}

These ten themes are the elementary building blocks in generating and maintaining an innovative, co-creative, and co-learning environment. Both the project culture and the values that are truly shared in the organization are essential for the well-being of people and their productivity, not to mention the importance of the tools for co-working and co-learning that the organization has to offer. The Toolbox elements enable an innovative environment for individual projects, higher-education institutions, and other organizations, including companies.

In addition to the ten Toolbox themes, three basic pillars - trust, respect, and joy - were identified as the core and foundation for the co-creative collaboration culture and innovative working and learning environment. These factors cannot be taken for granted, but they call for common values and managing of the organization's value culture. These three pillars, as well as sharing of 


\title{
Orchestrators of Innovation-Driven Regional Development
}

\author{
Mervi Rajahonka, Toni Pienonen, Riikka Kuusisto, and Jari Handelberg
}

common values, assure an energetic, safe, and innovative environment for project work:

- Trust: creating and maintaining an atmosphere of trust as a living thing between people and as part of the operating model and organization structure

- Respect: creating a safe environment where all ideas are welcome and highly respected, developing joint rules, fostering positive and constructive thinking and acting, sharing knowledge, and encouraging openness

- Joy: creating conditions where joy can be experienced in the act of co-creation and through its outcomes

All ten themes were discussed, tested, and further developed during the Change2020 programme. The themes were concretized into 10 wooden batons (Figure 1), which were used during co-creation activities, including the bench-learning workshops. Also, a Toolbox game-development competition was arranged. There were several ways discovered with respect to how the Toolbox batons could be used as physical objects for generating ideas in day-to-day work or in weekly or monthly meetings to improve the working practices and change the working culture towards more innovative and productive directions. For example, the "Being Visual" baton was used for discussing which practices were used when presenting information or publishing results in projects and, if the current practices were not satisfactory in visual terms, how they could be improved. The Toolbox game can be found at:

http://www.innofokus.fi

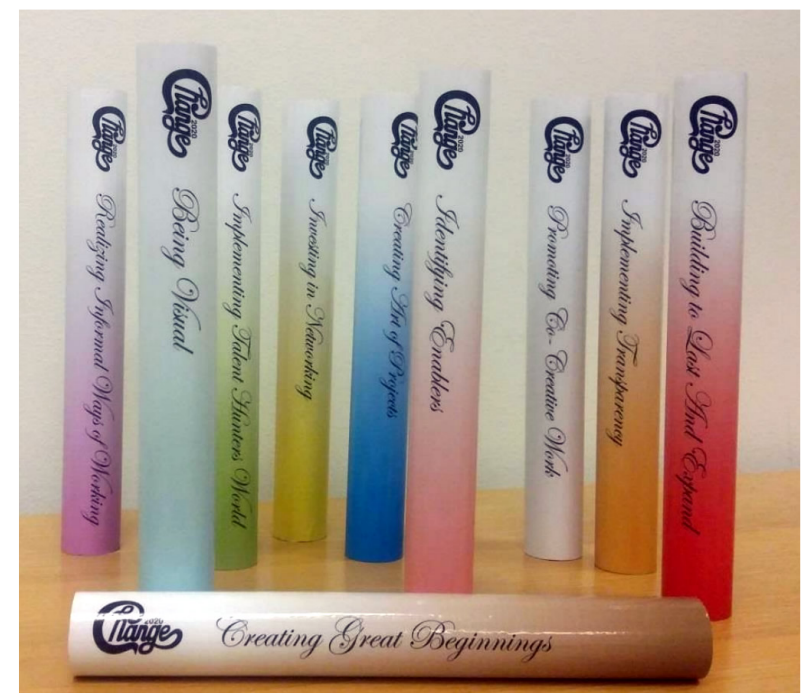

Figure 1. Toolbox batons, each representing one of the 10 themes

\section{Project Perspective: A Model for High-Impact Projects}

Following the thematic perspective, in this section we summarize the views of the Change2020 participants on prerequisites of higher-impact regional development projects into five learning points:

1. Remember that co-creation is where it all begins.

\section{Focus on the big picture.}

3. Create focus and relevance by building on strengths.

\section{Encourage agile experimentation.}

\section{Put learning at the core of development projects.}

We believe that these learning points are of practical value for project managers and designers and other $R \& D$ staff in higher-education institutions and regional development organizations, but also in other project organizations. Overall, it could be said that, in the past, many Finnish regional development projects were too planning-driven and were managed in closed systems. Risk taking has been minimized by rigid planning based on end results. These five learning points are summarized in the subsections below and are described in greater detail in one of the workbooks by Pienonen and Markkanen (2014b).

\section{Remember that co-creation is where it all begins}

Regional development projects must be: demand-driven and rooted in the needs of the surrounding economy and society; co-created together with users and partners; designed to follow the principles of open innovation (e.g., Kolehmainen, 2015). Society and business must be at the core of the projects from the initial planning phase. These projects bring out real-life problems, needs, opportunities, and wicked problems that are worth solving with the help of the higher-education institutions in projects. On this learning point, experiences from the Change2020 programme yielded the following recommendations:

- Identify and formulate the need or opportunity.

- Co-create the vision.

- Co-create the solution.

- Share active ownership. 


\title{
Orchestrators of Innovation-Driven Regional Development
}

\author{
Mervi Rajahonka, Toni Pienonen, Riikka Kuusisto, and Jari Handelberg
}

\section{Focus on the big picture}

Development projects are just tools to attain a desired level of change. They are always parts of something bigger - organizationally, regionally, and activity-wise. Specifically, projects managed by higher-education institutions must integrate their outcomes and outputs into the two other missions of the university: research and education. As much as possible, higher-education institutions should involve teachers, researchers, and students in project planning and execution. Their involvement creates spill-over benefits and integrates the explorative project work results exploitatively into the other missions of the university. (Brady \& Davies, 2004; Davey et al., 2011; Goddard \& Vallance, 2011). On this learning point, experiences from the Change 2020 programme yielded the following recommendations:

- Position the project in the portfolio of the organization, region, or nation.

- Manage organizational integration. For example, in projects managed by higher-education institutions, any activity undertaken in a project must be aligned to leverage and utilize the different types of university-society cooperation.

\section{Create focus and relevance by building on strengths}

Project managers should take a careful look at what kinds of skills and expertise are required to make their plans happen. Typical team-related problems in development projects are often two-fold. First, there may be a total lack of a team: one person (usually the project manager) may have to do everything. Second, the project manager is typically hired purely based on rather narrow professional competence requirements, but projects need a variety of skills - from organizing events to sales, productization, communication, and administration (bureaucracy). Furthermore, projects should make use of specific strengths that are unique to the project organization and region, making their uniqueness a value proposition for domestic and international partners. The project organization should look for the necessary knowledge and expertise from its partners, rather than trying to build everything from scratch itself. For example, universities of applied sciences can focus on adapting the results from research universities' newest technology studies to small and mediumsized businesses and build up their knowledge absorptive capacity with the help of regional development agencies, instead of trying to develop new technology themselves. On this learning point, experiences from the Change2020 programme yielded the following recommendations:
- Build a team of individuals with complementary competencies for different tasks.

- Leverage the complementary strengths of participating organizations and regions.

\section{Encourage agile experimentation}

Currently, Finnish project development remains too planning-driven. Instead, there should be more experimentation and agile processes. After all, one of the purposes of public development projects is to radically test new solutions that would otherwise be deemed too risky or unaffordable. When developing something entirely new, it is difficult to be certain of the results beforehand. This is why agile process and learning by experimenting - doing, testing, and failing - are needed in projects, as opposed to more planning-driven development. In this mindset, failure is a success; it merely proves that something does not work. In an experimentation-driven project model, the key driver is rapid learning in order to create something unique (Salmelin, 2015; Tuulenmäki, 2012). On this learning point, experiences from the Change2020 programme yielded the following recommendation:

- Experiment, pilot, and scale to market.

In Figure 2, we present an example of how to incorporate an experimentation-driven model into the structure of a public regional development project. At the beginning, the project sets out a clear vision. In the first phase of its journey (1), the project executes small-scale experiments to test suitable ways of reaching the goal. A project plan describes the number of pilots and gives a rough outline of how testing and analysis will be done to give reassurance for the financing authority. Then, the project analyzes the experiments, eliminates those methods that do not work, and continues with largerscale pilots (2). Finally, a scalable solution is born out of the best of three larger-scale pilots (3). Because the solution has undergone extensive real-life experimentation, there should be enough inertia and demonstration evidence to help it survive on its own.

Note that a similarly structured approach can be applied on a regional level. It starts out with a co-created vision by members of the innovation ecosystem that states what they want to achieve. This vision can be based on a common thematic area, for example, a societal challenge, issue, or a wicked problem; a regional smart specialization spearhead; or an emerging technology. First, regional actors carry out small-scale activities (i.e., lump sum projects) to demonstrate a variety of 


\title{
Orchestrators of Innovation-Driven Regional Development
}

\author{
Mervi Rajahonka, Toni Pienonen, Riikka Kuusisto, and Jari Handelberg
}

1

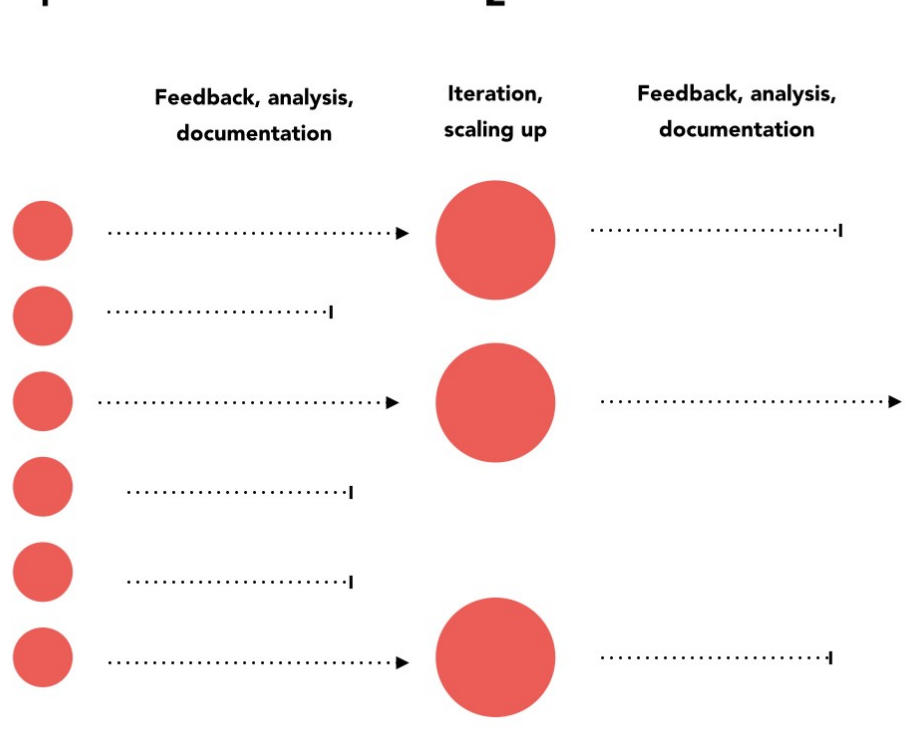

3

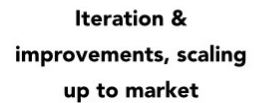

up to market

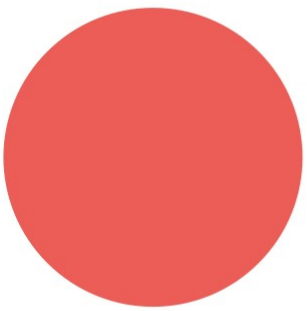

Figure 2. Incorporating an experimentation-driven model into the structure of a public regional development project

solutions before moving up to bigger projects. On this scale, the relevance of a shared vision grows ever more important, because different activities are likely to be implemented by a variety of actors, who all require a sense of common purpose to direct them.

\section{Put learning at the core of development projects}

By focusing on learning and self-reflection, it would be easier for projects and supporting authorities to talk about failures and mishaps without fear of punishment. Projects should reflect on what kinds of internal learning processes they use in practice. They should constantly ask themselves to what extent the results of the experiences are shared with the rest of the project organization, and how informed the stakeholders are of what is happening. With project work and its limited time, flawlessness should not be the goal. To make this happen, all projects should integrate a proper learning process into the project plan and organize time for people to experience it experimentally (e.g., Markkanen \& Pienonen, 2014; Nonaka \& Konno, 1998; Järvenpää \& Kankare, 2012). On this learning point, experiences from the Change2020 programme yielded the following recommendation:

- Focus on continuous learning and reflection, both externally and internally.

\section{Project Findings}

Based on the INNOFOKUS project and its Change2020 development programme, it can be concluded that, to achieve the aforementioned conditions for high-impact projects, an ongoing process of discovery and learning is needed, where everyone learns by doing, experiments, and participates socially. The participants of the Change2020 programme, for example, stated that a regional research and innovation strategy for smart specialization (RIS3) should not be a paper that is "written once and then forgotten in a drawer". This learning process should be supported and facilitated at several levels, as described by Klerkx and Aarts (2013) and Launonen (2015), or by creating Ba-like environments that promote the SECI cycle (i.e., socialization, externalization, combination, and internalization) (Konno, 2015; Nonaka \& Konno, 1998). The Change2020 participants identified several examples of good practices to enable this. For example, the Region of Kymenlaakso in Southeastern Finland embarked on a journey to shape their RIS3 strategy through an iterative co-creation process in which the steps themselves, not just the outcome, were perhaps just as important. This is only possible by creating venues - large and small - for interaction. Another good example of practice from Change2020 comes from Finnish Lapland (Box 1), a region where frequent staff exchange between regional project organizations (higher-education institutions, 


\title{
Orchestrators of Innovation-Driven Regional Development
}

\author{
Mervi Rajahonka, Toni Pienonen, Riikka Kuusisto, and Jari Handelberg
}

development agencies, regional authorities) allow their experts to simultaneously work for different organizations and projects. Given that most valuable project knowledge (tacit knowledge and social capital) is so strongly embedded in individual people - and is therefore difficult to transfer - regional developers in Lapland felt that one of the best ways to increase learning in ecosystems was "knowledge transfer on legs" via staff exchange.

Furthermore, to achieve higher impact, greater synergy in using different funding instruments is needed. In Finland, different funding instruments are currently managed by a plethora of funding authorities, often in disaccord and without a plan for the big picture. Although the official ethos surrounding the new European Union programme period 2014-2020 promises improvements, synergy cannot happen with words alone. A good practice case of a funding authority solving this particular challenge is from North-Karelia in Eastern Finland, where the two authorities responsible for grants - the European Social Fund (ESF) and the European Regional Development Fund (ERDF) - organized a three-phase open idea submission, commentary, and co-creation process for potential project organizers well before the actual funding call. The process took place online and in face-to-face workshops. This approach reduced overlapping project submissions and unnecessary competition. The role of funding authorities, as one of the quadruple helix parties, in enabling transparency and openness should not be understated.

Finally, to make this happen, any high-impact project ecosystems need orchestrators to guide the process and draw the big picture with an exciting vision. Based on the experiences of the Change2020 programme, the orchestrator can be a person (or a team of people) who takes the role (in an organization, a region, a network, or nationally) of transparently facilitating the development activity with information, resources, and learning. The Change 2020 participants experienced this personally at the Urban Mill (urbanmill.org) in Espoo, Finland, which also acted as a venue for one of the workshops. In addition to being a co-working and event space, the Urban Mill is also a thematic co-creation and co-development platform that also acts as a hands-on orchestrator in the theme of urban innovations in the Helsinki region, bringing citizens, academics, business people, and public actors together. It is more than just a science park or co-working space. Such thematic platforms that operate on both grassroots and strategic levels can be the strategic nodes from which the ecosystem gains the common direction.
Box 1. Lapland and its "Smart Strengths"

During a Change2020 workshop in Lapland, the participants found that, in addition to the regional strategic smart specialization and expertise in mining, tourism, and bioeconomics, Lapland has plenty of other strengths and characteristics that make it a unique region in Finland, Europe, and the world. Some of the strengths that outsiders noted include:

1. Global megatrends are likely to increase the significance of Arctic regions.

2. Active knowledge exchange and multitasking are typical in the daily work of Lapland's regional developers. This regional learning makes easier to transfer tacit knowledge.

3. The international aspect is everywhere in Lapland, which has three bordering countries: Sweden, Norway, and Russia. A long history of cross-border activity and good logistics connections make Lapland the most international region in Finland. International experience is one of its critical assets in development work.

4. Lapland is a perfect location for applying and testing technology in a unique setting. Although Lapland is not necessarily the best place for researching completely new things, Arctic conditions provide a unique setting for testing new technologies and solutions in extreme conditions.

The conditions under which the orchestrators must work within networks are very different from ordinary business environments. The Change 2020 process revealed that traditional management models and paths do not apply under such conditions, because networks are living systems of self-organization. Further confirming the view of Klerkx and Aarts (2013), it can be noted that networks of regional development projects cannot be controlled, only nudged in the right direction. The leadership in networks is shared and comes in different forms - as opposed to hierarchy and official leadership positions. Because of this, the above-mentioned shared vision is vital: it is the glue that binds together individual activities and gives a sense of purpose to all involved.

One of the most important conclusions based on the experiences of the Change 2020 programme is that innovation orchestrators play an important role in regional 


\title{
Orchestrators of Innovation-Driven Regional Development
}

\author{
Mervi Rajahonka, Toni Pienonen, Riikka Kuusisto, and Jari Handelberg
}

innovation. As proposed by Bror Salmelin (2015) from the Open Innovation Strategy and Policy Group (OISPG) of the European Commission Directorate General for Communications Networks, Content \& Technology (DG Connect), these orchestrators are the curators and bridgers, who: i) maintain the quality of content generated by different innovation players and the communities and ii) are inherently interested in everything, and they connect and create new linkages between people and organizations. Orchestrators facilitate key people with information, resources, and knowledge, as shown in Figure 3.

\section{Conclusions}

This article identified ways to enhance the efficient use of public funding instruments in regional innovation ecosystems by studying the prerequisites of an enriching and energizing project environment and high-impact project culture. The article has at least two kinds of generally applicable implications for innovation managers. First, the findings corroborate that the promotion of an enriching and energizing project environment and high-impact project culture requires a continuous learning and participation process. The applicability of results is not limited to publicly funded or regional innovation systems, but can be generalized into any kind of complex innovation network. Second, the results show that the key individuals, who can make the enriching and energizing project environment and high-impact project culture happen, are in-
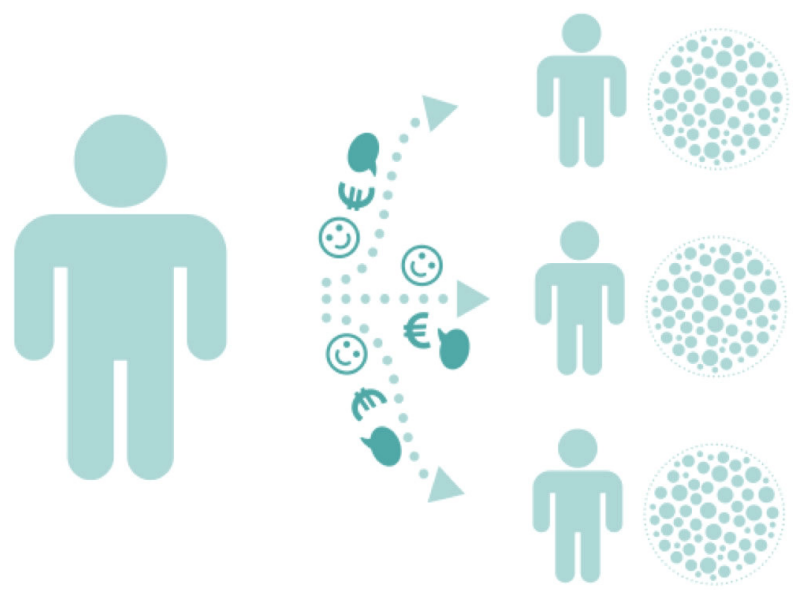

Figure 3. Orchestrators facilitate the activities of key people with information, resources, and knowledge novation orchestrators. The orchestrators facilitate activities and compose the big picture. They are the key actors for employing the full potential of innovation platforms, regions, and ecosystems.

Furthermore, we can draw at least two implications for policies supporting regional innovation ecosystems. First, because orchestrators and their work are essentially important in the regional innovation ecosystems, they should be recognized. Therefore, public recognition of this new profession needs to be strengthened, for example, by creating curricula and training that help to increase the meta-skillsets of orchestrators (e.g., facilitation, vision-setting, curation). Second, the role of an orchestrator should be built into all development projects and platforms from the get-go. This can either be a requirement by the funding authority for any prospective projects, or it can be facilitated by funding regional coordination projects that focus on enabling the orchestration work. In the long term, to avoid the buildup of unnecessarily bureaucratic and inefficient intermediary structures, regions and innovation communities should be open to experimenting success-feedriven models, where both the public and private innovation orchestrators receive compensation based only upon the results of their work.

\section{Acknowledgements}

This article is a further developed version of the chapter by J. Handelberg, R. Kuusisto, T. Pienonen, and M. Rajahonka (2015): "Co-creating Synergy: LearningDriven Regional Development", which was published in P. Lappalainen, M. Markkula, and H. Kune (Eds.), Orchestrating Regional Innovation Ecosystems: Espoo Innovation Garden: 209-220, by Aalto University in cooperation with Laurea University of Applied Sciences and Built Environment Innovations RYM Ltd. 


\title{
Orchestrators of Innovation-Driven Regional Development
}

\author{
Mervi Rajahonka, Toni Pienonen, Riikka Kuusisto, and Jari Handelberg
}

\section{About the Authors}

Mervi Rajahonka (D.Sc. (Econ)) works in the Aalto University School of Business Small Business Center (SBC) in Helsinki, Finland, as a project specialist and a researcher working with various research themes such as innovation, impact evaluation, and business and service models in areas such as creative industries, entrepreneurship, and logistics services. Mervi acted as a researcher in the INNOFOKUS project.

Toni Pienonen is a Project Designer at the Business Arena Oy in Jyväskylä, Finland, where he works on themes related to university-business cooperation, entrepreneurship, and participatory regional development. Toni acted as a facilitator in the INNOFOKUS Change2020 programme and is a co-author of the two programme workbooks.

Riikka Kuusisto works in the Aalto University School of Business Small Business Center (SBC) in Helsinki, Finland, and he was project manager of the INNOFOKUS project. She has nearly ten years of experience and expertise in innovation and knowledge management systems development. Riikka is also a specialist in e-learning, online collaboration, and online working models.

Jari Handelberg (D.Sc. (Econ)) is Research Director at the Aalto University School of Business Small Business Center (SBC) in Helsinki, Finland. He has long-term experience in managing EU-funded projects. His research interests focus on entrepreneurship and regional development. Jari was a member of the INNOFOKUS project steering group and was an active participant in the Change2020 programme.

\section{References}

Brady, T., \& Davies, A. 2004. Building Project Capabilities: From Exploratory to Exploitative Learning. Organisation Studies, 25(9): 1601-1621.

http://dx.doi.org/10.1177/0170840604048002

Davey, T., Baaken, T., Galan-Muros, V., \& Meerman, A. 2011. The State of European University-Business Cooperation Final Report - Study on the Cooperation between Higher Education Institutions and Public and Private Organisations in Europe. Münster, Germany: Science-to-Business Marketing Research Centre, Münster University of Applied Sciences.
Etzkowitz. H., \& Leydesdorff., L. 1995. The Triple Helix-University-Industry-Government Relations: A Laboratory for Knowledge-Based Economic Development. EASST Review, 14(1): 14-19.

Freeman, C. 1988. Japan: A New National System of Innovation? In G. Dosi, C. Freeman, R. R. Nelson, G. Silverberg, \& L. Soete (Eds.), Technical Change and Economic Theory. London: Pinter.

Goddard, J., \& Vallance, P. 2011. The Civic University: Re-Uniting the University and the City. Paper presented at the OECD Conference: Higher Education in Cities and Regions: For Stronger, Cleaner and Fairer Regions, February 10-11, Seville, Spain.

Järvenpää, T., \& Kankare, I. 2013. Veikö Moolok vallan? Vapauta projektisi tuhlaajakultista. [Did Moloch Take Over? Release Your Project from the Big Spender Cult.] Helsinki: Talentum.

Kempton, L., Goddard, J., Edwards, J., Hegyi, F. B., \& Elena-Pérez, S. 2014. Universities and Smart Specialisation. JRC Technical Reports; S3 Policy Brief Series No. 03/2013. Seville, Spain: Institute for Prospective and Technological Studies, Joint Research Centre.

Klerkx, L., \& Aarts, N. 2013. The Interaction of Multiple Champions in Orchestrating Innovation Networks: Conflicts and Complementarities. Technovation, 33(6-7): 193-210.

http://dx.doi.org/10.1016/j.technovation.2013.03.002

Kolehmainen, J., Irvine, J., Stewart, L., Karacsonyi, Z., Szabó, T., Alarinta, J., \& Norberg, A. 2015. Quadruple Helix, Innovation and the Knowledge-Based Development: Lessons from Remote, Rural and Less-Favoured Regions. Journal of the Knowledge Economy, Published online: September 3, 2015. http://dx.doi.org/10.1007/s13132-015-0289-9

Konno, N. 2015. "Ba" and Open Innovation: A View from Japan. Paper presented at the Open Innovation 2.0 Conference, Espoo, Finland, June 8, 2015.

Launonen, L. 2015. Determinants for Orchestrating Open Innovation Networks. In P. Lappalainen, M. Markkula, \& H. Kune (Eds), Orchestrating Regional Innovation Ecosystems: Espoo Innovation Garden: 199-208. Espoo: Aalto University in cooperation with Laurea University of Applied Sciences and Built Environment Innovations RYM Ltd.

Lundvall, B.-Å. 1985. Product Innovation and User-Producer Interaction, Industrial Development. Research Series 31. Aalborg: Aalborg University Press.

Markkanen, M., \& Pienonen, T. 2014. Hankemaailman Skynet ja muita tarinoita kannattavampaan kehittämistyöhön. [Project World's Skynet and Other Tales for More Profitable Development Work]. Jyväskylä, Finland: Business Arena Oy.

Nonaka, K., \& Konno, N. 1998. The Concept of "Ba": Building Foundation for Knowledge Creation. California Management Review, 40(3): 40-54.

Pienonen, T., Markkanen, M., Widgren, P., Davey, T., \& Galan-Muros, V. 2014. Operaatio Metsonpesä - Korkeakoulujen työelämäyhteistyön tilannekuva haltuun. [Operation Metsonpesä - Flash Picture of the Collaboration of HEIs and Working Life]. Project report. Jyväskylä, Finland: Business Arena Oy.

Pienonen, T., \& Markkanen, M. 2014a. RIS3 Workbook for Learning Driven Regional Development: For Project Organizations, Regions and Project Consortiums Involved in Regional Development Projects, INNOFOKUS Change2020 Workbook A: http://www.innofokus.fi/ris3+workbooks+hanketoiminnan+uusi+ malli+-tyokalut/ 


\section{Orchestrators of Innovation-Driven Regional Development Mervi Rajahonka, Toni Pienonen, Riikka Kuusisto, and Jari Handelberg}

Pienonen, T., \& Markkanen, M. 2014b. RIS3 Workbook for Projects: For Project Managers, Designers, R\&D Staff and Regional Development Organizations, INNOFOKUS Change2020 Workbook B:

http://www.innofokus.fi/ris3+workbooks+hanketoiminnan+uusi+ malli+-tyokalut/

Ritala, P., Armila, L., \& Blomqvist, K. 2009. Innovation Orchestration Capability - Defining the Organisational and Individual Level Determinants. International Journal of Innovation Management, 13(4): 569-591.

http://dx.doi.org/10.1142/S136391960900242X
Salmelin, B. 2015. Opening Ceremonies and Plenary. Open Innovation 2.0 Conference, Espoo, Finland, June 8, 2015.

Tuulenmäki, A. 2012. Lupa toimia eri tavalla. [Licence to Act Differently]. Helsinki: Talentum.

Citation: Rajahonka, M., Pienonen, T., Kuusisto, R., Handelberg, J. 2015. Orchestrators of Innovation-Driven Regional Development:

Experiences from the INNOFOKUS Project and the Change2020 Programme. Technology Innovation Management Review, 5(10): 52-62.

(cc) BY http://timreview.ca/article/937

Keywords: regional development, regional innovation ecosystem, orchestrator, high-impact projects, experimentation-driven development, agile project development, smart specialization, smart specialisation 